\title{
Mechanism of Mitogen-induced Stimulation of Glucose Transport in Human Peripheral Blood Mononuclear Cells

\author{
Evidence of an Intracellular Reserve Pool of Glucose Carriers and Their Recruitment
}

David B. Jacobs, Tee-Ping Lee, Chan Y. Jung, and Basab K. Mookerjee

Department of Medicine and Biophysics Laboratory, Veterans Administration Medical Center, State University of New York at Buffalo, Buffalo, New York 14215

\begin{abstract}
The present study examines the effects of phytohemagglutinin stimulation of a population of human (h) PBMC enriched in lymphocytes (hPBMC) on D-glucose displaceable cytochalasin B binding sites or medium-affinity sites (M-sites) in relation to glucose transport. Previously we have shown that $\mathbf{M}$-sites are glucose transporters in hPBMC (Mookerjee, B. K., et al. 1981. J. Biol. Chem. 256:1290-1300). Equilibrium exchange of 3-Omethyl D-glucose in unstimulated cells revealed two populations with fast and slow flux rates. Phytohemagglutinin stimulates flux rates by converting part of the slow flux population to the fast flux population. M-sites occur in two distinct pools, one in plasma membrane and the other in microsomal fraction. Phytohemagglutinin treatment increases the plasma membrane pool size of $M$-sites with a concomitant reduction in the microsomal pool size without affecting the binding affinities or the total number of $\mathrm{M}$-sites/cell. Data presented in this paper demonstrate that there are two pools of glucose transporters in these cells and phytohemagglutinin stimulation induces an energy-dependent net translocation of glucose transporters from an intracellular reserve pool to the plasma membrane, which accounts for $>60 \%$ of the increment in glucose transport.
\end{abstract}

\section{Introduction}

Plant lectins such as PHA trigger resting lymphocytes into metabolic activity. Several groups of investigators have shown that one of the earliest effects of the lectin binding to the lymphocyte is the enhancement in glucose transport (1-8). Peters and Hausen (1) have shown that increase in 3-O-methyl glucose (3-OMG) ${ }^{1}$ uptake in lymphocytes was demonstrable within minutes of exposure to PHA and is independent of de novo protein synthesis. They also showed that the augmented transport in PHA-stimulated lymphocytes is due to an increase in the $V_{\max }$ without significant change in the half-saturation

Address reprint requests to Dr. B. K. Mookerjee, Department of Medicine, Veterans Administration Medical Center, 3495 Bailey Avenue, Buffalo, NY 14215.

Received for publication 5 February 1987 and in revised form 20 July 1988.

1. Abbreviations used in this paper: $\mathrm{ABS}$, human blood group $\mathrm{AB}$ serum; $\mathrm{B}_{\mathrm{T}}$, total binding capacity; $\mathrm{CB}$, cytochalasin B; 2DOG, 2deoxy-D-glucose; $K_{\mathrm{m}}$, half-saturation constant; M-site, medium-affinity site; $5^{\prime}$-NT, $5^{\prime}$-nucleotidase; 3-OMG, 3-O-methylglucose; $t_{1 / 2}$, half equilibration time.

The Journal of Clinical Investigation, Inc.

Volume 83, February 1989, 437-443 constant $\left(K_{\mathrm{m}}\right)$. The authors interpreted these findings as an increase inthe number of functional glucose carriers in the Con A, another lectin, and calcium ionophore (A23187) were also shown to stimulate glucose transport in calcium-dependent fashions in rat thymocytes $(2,4)$. These early effects on glucose transport are independent of insulin since insulin receptors do not express themselves until $4 \mathrm{~h}$ or longer after PHA stimulation (3).

The glucose transport in lymphocytes proceeds via a mechanism of facilitated diffusion similar to that in adipocytes (1) and is specifically inhibited by a fungal metabolite, cytochalasin B (CB) (9). Recently, two groups of workers have provided evidence that the mechanism by which insulin enhances glucose transport in adipocytes involves net translocation of glucose carrier molecules from an intracellular pool to the outer plasma membrane $(10,11)$. Thus, it was interesting to investigate whether stimulation of glucose transport in lymphocytes immediately after 30-60 min of PHA treatment, a time period known to be too short for emergence of a significant amount of insulin receptors, also involves a recruitment of glucose transporters from an intracellular storage pool to the cell surface.

The number of transport carrier molecules in adipocytes (10) and human erythrocytes (12) has been quantitated by measuring glucose-sensitive CB binding sites. Previously we have described three distinct classes of $\mathrm{CB}$ binding sites in a population of human (h) PBMC enriched in lymphocytes ( $\sim 88 \%$ lymphocytes) and identified the medium-affinity site (M-site) that was specifically displaced by D-glucose as the glucose carrier $(9,13)$. In the present study we first show that the M-site occurs not only in the plasma membrane but also in a microsomal fraction as an intracellular reserve pool. Second, we show that net translocation of M-sites from the microsomal reserve pool to the plasma membrane occurs upon stimulation with PHA. We also demonstrate that such recruitment accounts for a significant part $(60 \%)$ of the augmentation in glucose transport that occurs immediately after PHA stimulation. Since we have studied transport effects without insulin and only during the first 30-60 min after PHA stimulation before emergence of insulin receptors, the observed effects include only the early effects of PHA on glucose transport that are not mediated by insulin.

\section{Methods}

Materials. Parker's medium 199 was obtained from Gibco Laboratories, Grand Island, NY. 3-O-methyl-D-glucose, D- and L-glucose, 2deoxy-D-glucose (2DOG), CB, and cytochalasin $\mathrm{E}$ were purchased from Sigma Chemical Co., St. Louis, MO. $\left[{ }^{3} \mathrm{H}\right] \mathrm{CB},\left[{ }^{3} \mathrm{H}\right] 2$-deoxy-glucose, and 3-O-methyl- $\left[{ }^{3} \mathrm{H}\right]$ glucose were purchased from New England Nuclear, Boston, MA. All other chemicals were standard commercial products of reagent grade quality. PHA was purchased from Burroughs-Wellcome, Research Triangle Park, NC. 
Preparation of cells. Platelet pheresis residue or buffy coat bags obtained from the Red Cross Blood Bank were used as cell source, which provided the very large number of cells required, as described by Lichtman et al. (14). Mononuclear leukocytes were first prepared from these sources by Ficoll-Hypaque density gradient centrifugation as described previously from our laboratory (15). The cell population was then depleted of adherent cells, monocytes, B cells, and platelets. For this, the mononuclear cells were suspended in medium 199 containing $10 \%$ human blood group $\mathrm{AB}$ serum (ABS) and incubated in a glass bottle previously coated with $\mathrm{ABS}$ for $1 \mathrm{~h}$ at $37^{\circ} \mathrm{C}$. The nonadherent cells were gently decanted. The suspension was centrifuged at low speed $(200 \mathrm{~g})$ for $10 \mathrm{~min}$, and the pellet was resuspended in medium 199 and treated with $0.83 \%$ ammonium chloride for $5 \mathrm{~min}$ to lyse residual red blood cells and platelets. The cell suspension was again centrifuged at $200 \mathrm{~g}$ for $10 \mathrm{~min}$ and the pellet was washed once. At this point the composition of the cell population in the suspension was determined in four separate experiments. The cell population was found to consist of $88.0 \pm 2.7 \%$ (mean \pm SE) lymphocytes and $11.5 \pm 2.7 \%$ monocytes by examination of smears stained by Wright's stain. By using the Quantigen rosette assay (Ortho Pharmaceutical, Raritan, NJ), there were $74.0 \pm 2.2 \%$ T cells and $2.2 \pm 1.3 \%$ B cells in this population. This population will henceforth be referred to simply as hPBMC.

PHA treatment. Washed hPBMC were resuspended in medium 199 and incubated with and without PHA at $37^{\circ}$ for $40 \mathrm{~min}$ before washing and subcellular fractionation (total time of exposure to PHA including washing $=\sim 60 \mathrm{~min}$ ). We chose to use PHA at a concentration of $5 \mu \mathrm{g} / \mathrm{ml}$ since in our laboratory peak DNA synthesis of stimulated cells is usually maximal at this concentration. For example, after $72 \mathrm{~h}$ culture of $10^{5}$ lymphocytes under previously described conditions (9), PHA at $5 \mu \mathrm{g} / \mathrm{ml}$ caused an increment in tritiated thymidine uptake over control (unstimulated hPBMC) of 14,823 $\pm 2,304$ (mean \pm SE, $n$ =3). At higher PHA concentrations the increment was less than maximal $(8,699 \pm 1,992 \mathrm{cpm}$ at $10 \mu \mathrm{g} / \mathrm{ml})$ until toxic concentrations were reached.

Subcellular fractionation. Cells were resuspended at a concentration of $10^{7} / \mathrm{ml}$ in homogenization buffer $(255 \mathrm{mM}$ sucrose, $1 \mathrm{mM}$ EDTA, and $10 \mathrm{mM}$ Tris, $\mathrm{pH} 7.4$, to be referred to as SET) and homogenized by 10 strokes of a Teflon-glass homogenizer (Thomas Scientific, Swedesboro, NJ). Subcellular fractions were prepared as described (16, 17) essentially following the procedure of Cushman and Wardzala (10). The homogenate was centrifuged at $17,000 \mathrm{~g}$ for $15 \mathrm{~min}$ at $4^{\circ} \mathrm{C}$, and the supernatant and pellet were saved. The pellet was washed and centrifuged at $110,000 \mathrm{~g}$ for $70 \mathrm{~min}$ in a discontinuous $1.12 \mathrm{M}$-sucrose gradient in $20 \mathrm{mM}$ Tris $\mathrm{HCl}$ and $1 \mathrm{mM}$ EDTA. The resulting plasma membrane-enriched band was washed twice by centrifugation at $48,000 \mathrm{~g}$ and resuspended in the assay buffer at a protein concentration of $3-5 \mathrm{mg} / \mathrm{ml}$. The $17,000 \mathrm{~g}$ supernatant was centrifuged at $200,000 \mathrm{~g}$ for $70 \mathrm{~min}$ to yield the microsomal fraction as pellet, which was similarly resuspended in the assay buffer as described from our laboratory $(16,17)$.

Measurement of 3-OMG transport. hPBMC were resuspended in Dulbecco's buffered saline solution and incubated with $5 \mu \mathrm{g} / \mathrm{ml}$ of PHA for $30 \mathrm{~min}$ at $37^{\circ} \mathrm{C}$. The corresponding control contained no lectin. Equilibrium exchange influx of 3-OMG was measured by following a 40-min time course of radioactive tracer uptake using $\left[{ }^{3} \mathrm{H}\right] 3-$ OMG $(1 \mu \mathrm{Ci} / 0.36 \mathrm{ml})$ as follows: cells were incubated in $10 \mathrm{mM}$ 3-O-methyl-D-glucose for $30 \mathrm{~min}$ at $37^{\circ} \mathrm{C}$ after which they were cooled to $15^{\circ} \mathrm{C}$. At $t=0$ the radioactive tracer was added and kept for a defined period of time. Flux was stopped by addition of $1 \mathrm{ml}$ ice-cold buffer containing $2 \mathrm{mM} \mathrm{HgCl}_{2}$ and the tubes were centrifuged at $4^{\circ} \mathrm{C}$ to separate the pellet. The radioactivities of both the medium and the cell pellet were determined by liquid scintillation counting (LS 90,000; Beckman Instruments, Inc., Palo Alto, CA).

Measurement of $2 D O G$ uptake. Fresh hPBMC were suspended in MEM at a concentration of $10^{7}$ cells $/ \mathrm{ml}$ at $37^{\circ} \mathrm{C}$. Aliquots $(0.5 \mathrm{ml})$ of this suspension were incubated for defined lengths of time with or without PHA with a tracer amount of $\left[{ }^{3} \mathrm{H}\right] 2 \mathrm{DOG}$ (specific activity, 5
$\mathrm{Ci} / \mathrm{mmol}, 2 \mu \mathrm{Ci} / \mathrm{ml}$ of cell suspension for assay). The $2 \mathrm{DOG}$ transport was then terminated by washing and resuspension in buffer at $4^{\circ} \mathrm{C}$. The cells were separated from supernatant by centrifugation and the cell pellet-associated radioactivity was measured by liquid scintillation counting as above.

$C B$ binding assay. D-Glucose displaceable (M-sites) CB binding to intact lymphocytes was assayed by the centrifugation method described previously from our laboratory $(9,16)$. For measurement of binding to purified subcellular membrane fractions, a given amount $(35-50 \mu \mathrm{g} / \mathrm{ml})$ of membrane preparation was suspended in SET buffer containing $500 \mathrm{mM} \mathrm{L}$ - or D-glucose, $10^{-5} \mathrm{M}$ cytochalasin $\mathrm{E}$, and a varying concentration of $C B$ with a fixed, tracer amount of $\left[{ }^{3} \mathrm{H}\right] \mathrm{CB}$ in $230-\mu 1$ cellulose proprionate centrifuge tubes (Beckman Instruments, Inc.). Tubes were then incubated for $45 \mathrm{~min}$ at $4^{\circ} \mathrm{C}$ and subsequently centrifuged at $200,000 \mathrm{~g}$ for $1 \mathrm{~h} .100 \mu \mathrm{l}$ of supernatant was removed for counting. The remaining supernatant was completely aspirated and the pellets were solubilized with $2 \%$ SDS overnight and were transferred to a scintillation vial. Radioactivities of both supernatants and pellets were counted in a scintillation counter (LS 9,000; Beckman Instruments, Inc.). D-Glucose-displaceable M-site CB binding (17) was calculated from the difference in observed binding in the absence and presence of $500 \mathrm{mM}$ D-glucose. Data were subjected to Scatchard plot analysis for the quantitation of M-sites. Where effects of low temperature were assessed, lymphocytes were incubated with and without PHA at $4^{\circ} \mathrm{C}$ for $40 \mathrm{~min}$, followed by preparation of subcellular fractionation and measurement of $\mathrm{CB}$ binding as described above.

Measurement of lactate production and ATP content. hPBMC were suspended in Dulbecco's buffered saline solution at a concentration of $2 \times 10^{6}$ cells $/ \mathrm{ml}$ and incubated with and without PHA at $37^{\circ} \mathrm{C}$. The incubation was terminated after designated periods of time as given in the figures by addition of TCA to a final concentration of $6 \%$. The assay mixture was vortexed, allowed to stand at $0^{\circ} \mathrm{C}$ for $5 \mathrm{~min}$, and centrifuged $(1,000 \mathrm{~g}$ for $10 \mathrm{~min})$. The supernatant fluid was used for determination of ATP and lactate (18-20). For the measurement of ATP we took advantage of the fact that it reacts with 3-phosphoglycerate to form 1,3-diphospho-glycerate. The concentration of ATP is proportional to the amount of NADH reduced, which was monitored by the decrease in absorbance at $340 \mathrm{~nm}$ (18). For the measurement of lactate, the supernatant fluid was incubated with lactate dehydrogenase in the presence of NAD, as described (20). Lactate concentration in the sample was estimated by measurement of the increase in absorbance at $340 \mathrm{~nm}$ (20). Appropriate concentrations of KCN or DNP were incorporated into the incubation medium for specific experiments as depicted in the relevant figures and legends.

Measurement of $\mathrm{CO}_{2}$ production from ${ }^{14} \mathrm{C}$-labeled glucose. Freshly purified hPBMC were suspended in KRB at a cell concentration of 15 $\times 10^{6} \mathrm{cells} / \mathrm{ml}$. Assay was performed in a $37^{\circ} \mathrm{C}$ water bath in a flask of $2 \mathrm{ml}$ of KRB containing $1 \mathrm{mg} / \mathrm{ml}$ of unlabeled D-glucose, $0.22 \mu \mathrm{Ci} / \mathrm{ml}$ of $\mathrm{U}-\left[{ }^{14} \mathrm{C}\right]$ glucose, and $10 \% \mathrm{ABS}(20) .1 \mathrm{ml}$ of the cell suspension was added along with $10 \mu \mathrm{l}$ of PHA (final concentration $5 \mu \mathrm{g} / \mathrm{ml}$ ) to begin the assay. Controls contained no cells $(1 \mathrm{ml}$ of KRB being added instead), the full assay mixture with cells but no isotope, and the full assay mixture with cells but no PHA. The incubation was continued for defined periods of time at $37^{\circ} \mathrm{C}$ as described in Results, terminated by the addition of TCA, and incubated further for $1 \mathrm{~h}$. Plastic wells were removed from the flasks and the radioactivity in the well was counted by liquid scintillation in $10 \mathrm{ml}$ of Betafluor (National Diagnostics, Manville, NJ) (20). Background counts were deducted whenever indicated.

Statistical analysis. Statistical analysis was performed using the $t$ test, paired or unpaired, wherever appropriate, as indicated in the text.

\section{Results}

Fig. 1 demonstrates that treatment of the hPBMC with PHA stimulates both lactate production $(A)$ and glucose utilization measured by $\mathrm{CO}_{2}$ production $(B)$. The stimulation occurred almost instantaneously. Other workers have also demon- 

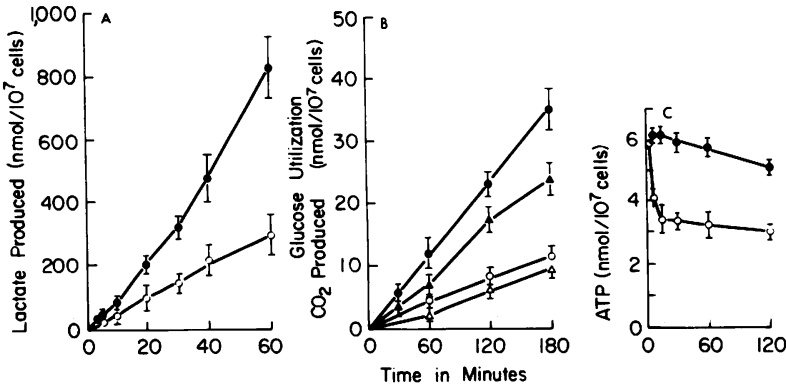

Figure 1. Effects of PHA on lactate production, glucose utilization, and ATP content in hPBMC. $(A)$ 60-min time course of the lactate production by PHA-stimulated cells (closed circles) was compared with that of unstimulated cells (open circles). Each data point represents a mean of three experiments with SEM shown as bar. $(B)$ Glucose utilization as measured by $\mathrm{CO}_{2}$ production from ${ }^{14} \mathrm{C}$-labeled glucose. Mean values of three experiments are plotted with one SEM Closed and open circles represent PHA-stimulated and unstimulated cells, respectively. Closed and open triangles represent stimulated and unstimulated hPBMC, respectively, both done in the presence of $1 \mathrm{mM}$ DNP. $(C)$ The ATP content of PHA-stimulated cells measured in the absence (closed circles) and presence (open circles) of 1 mM DNP, respectively. Mean values of two experiments along with SE thereof are plotted. Experimental methods used have been described in detail in Methods.

strated that activation of transport function in $\mathrm{T}$ lymphocytes with Con A and PHA is a rapid process (1-6). After $60 \mathrm{~min}$ of exposure to $\mathrm{PHA}$, lactate and $\mathrm{CO}_{2}$ production from glucose were enhanced by $2.8(P<0.05, n=3)$ - and $2.7(P<0.05, n$ $=3$ )-fold, respectively. Effects of a metabolic inhibitor on PHA-stimulated cells were shown in Fig. $1, B$ and $C .1 \mathrm{mM}$ DNP treatment inhibited $\mathrm{CO}_{2}$ production at $1 \mathrm{~h}$ by $\sim 60 \%$ in both control and PHA-treated cells $(B)$. In $C$, treatment reduced ATP content in PHA-stimulated cells very rapidly by 40-50\%.

The effects of PHA on glucose transport were next studied by measuring equilibrium exchange flux of 3-OMG. Preliminary experiments in this study indicated that at $37^{\circ} \mathrm{C}$ the equilibrium exchange is very rapid and therefore difficult to quantitate precisely. The rate of equilibration, however, was considerably reduced at $15^{\circ} \mathrm{C}$ so the entire 60 -min time course of the exchange could be followed accurately. Such a temperature effect was also reported by Peters and Hansen in their original description of the effect of PHA on glucose transport where the increment could be clearly shown only at $15^{\circ} \mathrm{C}(1)$. Results of a typical experiment are illustrated in Fig. $2 \mathrm{~A}$, revealing that PHA treatment significantly increases the rate of 3-OMG exchange as compared with unstimulated controls. The time courses of equilibration, when analyzed based on simple equilibration in a closed, two-compartment system, revealed two distinct first-order components (a slow and a fast) for both unstimulated (control) and PHA-stimulated lymphocytes (Fig. $2 A$ inset). For unstimulated hPBMC, the slow component showed a half equilibration time $\left(t_{1 / 2}\right)$ of $\sim 15 \mathrm{~min}$, while that of the fast component was $\sim 3 \mathrm{~min}$. The relative sizes of the two components were $\sim 80$ and $20 \%$, respectively. For PHAstimulated cells both of these components were observed with essentially identical $t_{1 / 2}$ values as those of unstimulated cells, but the relative sizes were 60 and $40 \%$. PHA treatment increased the size of the fast component almost twofold with a
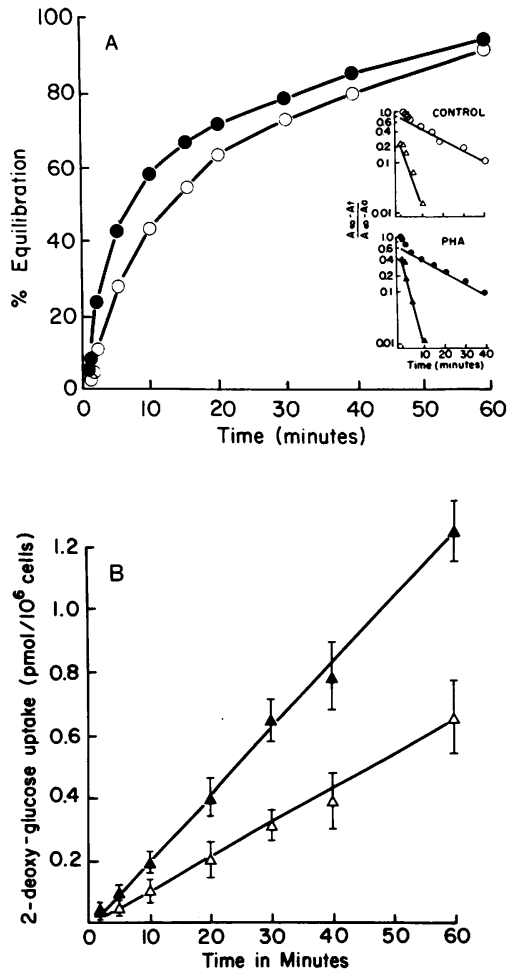

Figure 2. $(A)$ Time course of equilibrium 3$O$-methyl-U- $\left[{ }^{14} \mathrm{C}\right]$ glucose uptake. Closed circles represent PHAstimulated cells; open circles represent unstimulated control. Derived data for compartmental analysis are presented (inset). Inset shows overall flux data (circles) and derived data for fast compartment (triangles). (B) Time course of net 2-deoxyglucose uptake in unstimulated and PHA-stimulated cells. Closed triangles represent PHA-stimulated hPBMC; open triangles represent unstimulated hPBMC (mean and one $\mathrm{SE}$ in two experiments).

concomitant reduction in that of the slow component. This experiment was reproducible.

Since it is known that lowering the temperature to $15^{\circ} \mathrm{C}$ by itself can cause some redistribution of glucose transporters to the plasma membrane pool in adipocytes, we did some experiments in which $2 \mathrm{mM} \mathrm{KCN}$ was added after incubation of cells in PHA for $30 \mathrm{~min}$ at $37^{\circ} \mathrm{C}$ and incubation continued for $10 \mathrm{~min}$ at $37^{\circ} \mathrm{C}$. The temperature was then lowered to $15^{\circ} \mathrm{C}$ and equilibrium exchange of 3-MOG determined. Under these conditions both fast and slow flux components were still observed with $t_{1 / 2}$ times of $\sim 3$ and $15 \mathrm{~min}$, respectively, for both unstimulated and stimulated cells. For unstimulated cells the relative sizes of the fast and slow transporting components in the first experiment constituted 25 and $75 \%$, while in the second experiment the corresponding component sizes were 28 and $72 \%$. For PHA-stimulated lymphocytes the fast and slow components were 48 and $52 \%$ in the first experiment and 45 and $55 \%$ in the second experiment, respectively. Thus, most of the PHA-induced increment was still observed when $\mathrm{KCN}$ was used before the temperature shift. Therefore, most of the augmentation in transport and the increase in the size of the fast transporting component is due to PHA stimulation and cannot be attributed entirely to temperature shift. To avoid temperature shift altogether in demonstrating increment in glucose transport, we performed experiments using 2DOG. Transport of $2 \mathrm{DOG}$ was comparatively slow at $37^{\circ} \mathrm{C}$ (Fig. 2 $B)$. We were able to demonstrate a $1.8-2.0$-fold increase in 2DOG uptake due to PHA stimulation at $37^{\circ} \mathrm{C}$.

We have previously identified medium affinity D-glucose displaceable CB binding sites (M-sites) in hPBMC and presented evidence that these sites are the glucose transport carrier (9). Results in Fig. 3 show that the D-glucose displacement CB binding sites are found not only in the plasma membrane fraction but also in the microsomal membrane fraction of unstimulated human cells. The total binding capacity $\left(B_{T}\right)$ for 

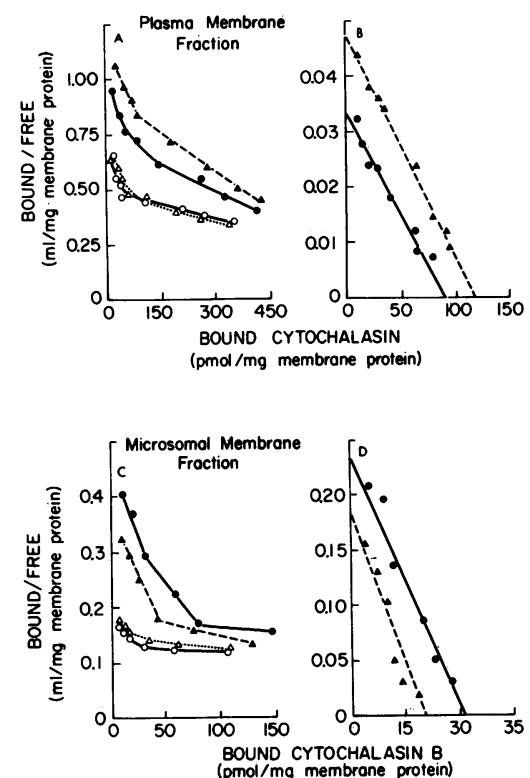

$\mathrm{mM}$ of D-glucose and Scatchard plots presented in $A$ and $C$. Derived Scatchard plots for D-glucose displaceable portion of the binding $(B$ and $D$ ) were constructed by subtracting (along radial axes of constant free CB concentration) each curve obtained in the presence of D-glucose from its respective curve obtained in the absence of D-glucose and analyzing the resulting values by simple linear regression as described $(9,11)$.

M-sites per milligram protein obtained by Scatchard plot analyses revealed that $M$-sites in unstimulated cells are almost three times more concentrated in the plasma membrane pool than in the microsomal pool (Tables I and II). Fig. 3 also illustrates that PHA treatment causes an increase in $B_{\mathrm{T}}$ of the M-site binding in the plasma membrane with a concomitant decrease in $B_{T}$ of the binding in the microsomal membrane. The $K_{d}$ for M-site binding in the microsomal membrane was found to be slightly but consistently lower than that in the plasma membrane. The PHA treatment, however, did not alter the $K_{\mathrm{d}}$ of this binding. These findings are reproduced quantitatively in several mutually independent experiments (Tables I and II). The $\mathrm{B}_{\mathrm{T}}$ of $\mathrm{M}$-sites in untreated and PHAtreated plasma membranes are $94.8 \pm 5$ (mean \pm SEM) and
124.9 $\pm 6.4 \mathrm{pmol} / \mathrm{mg}$ protein, respectively $(P<0.01, n=9)$. The PHA treatment increased the amounts of M-sites in plasma membranes by $26.1 \pm 2 \%$, (mean \pm SEM, $n=9)$. In the microsomal fraction the corresponding $B_{T}$ was $33.6 \pm 1.9$ $\mathrm{pmol} / \mathrm{mg}$ for untreated cells and $24.8 \pm 2.3 \mathrm{pmol} / \mathrm{mg}$ for PHAtreated cells, a reduction of $31.2 \pm 3.5 \%(P<0.01, n=9)$.

To determine if new glucose transporters are synthesized in the first 60 min of PHA stimulation, D-glucose-displaceable CB binding was measured in intact hPBMC. In three separate experiments the total binding capacity of D-glucose-displaceable CB binding (M-sites) in unstimulated control lymphocytes was $14.1 \pm 2.1 \mathrm{pmol} / \mathrm{mg}$ protein, while cells incubated for $60 \mathrm{~min}$ at $37^{\circ} \mathrm{C}$ with PHA had a total M-site binding capacity of $13.6 \pm 1.6 \mathrm{pmol} / \mathrm{mg}$ protein. The difference was not statistically significant, showing that there is no demonstrable net increment in M-sites during the first 60 min after PHA stimulation. This evidence argues against a net increase due to synthesis of new transporters or activation of inactive transporters during the first $60 \mathrm{~min}$ of PHA stimulation studied here. Therefore, these findings indicate an apparent redistribution (translocation) of the glucose-displaceable CB binding sites from microsomes to plasma membrane upon PHA treatment.

The PHA-induced translocation of M-sites appears to be energy dependent. When PHA treatment was carried out at $0^{\circ} \mathrm{C}$ (on an ice bath) no significant PHA-induced translocation of M-sites was observed (Table II). Metabolic inhibitors DNP ( $1 \mathrm{mM}$ ) and $\mathrm{KCN}$ ( $1 \mathrm{mM}$ ) (Table II) reduce the PHA-induced translocation of M-sites by 80 and $60 \%$, respectively. However, they did not cause significant changes in the $K_{\mathrm{d}}$ of the M-site binding in either fraction (Table II). Unlike the effects observed at $0^{\circ} \mathrm{C}$ neither DNP nor $\mathrm{KCN}$ totally obliterate the apparent redistribution of $\mathrm{M}$-sites. This is probably related to the fact that anaerobic metabolism generates a significant amount of ATP in hPBMC as evidenced by data presented in Fig. 1.

The data presented in Table III show that PHA treatment does not alter the specific activity of $5^{\prime}$-nucleotidase $\left(5^{\prime}-\mathrm{NT}\right)$ or the yield of protein in any of the subcellular fractions.

\section{Discussion}

Translocation of glucose carrier from an intracellular reserve pool to the plasma membrane pool as a major transport regu-

Table I. Effect of PHA Treatment on Glucose-sensitive CB Binding to the Plasma Membrane and Microsomal Membrane Fraction of hPBMC

\begin{tabular}{|c|c|c|c|c|c|c|}
\hline \multirow{2}{*}{$\begin{array}{l}\text { Lymphocyte } \\
\text { preparations }\end{array}$} & \multicolumn{3}{|c|}{ Plasma membranes } & \multicolumn{3}{|c|}{ Microsomal membranes } \\
\hline & Control & PHA & $\%$ Changes $*$ & Control & PHA & \% Changes* \\
\hline \multirow[t]{2}{*}{1} & $99.3(2.62)$ & $125.7(2.10)$ & +21.0 & $37.6(1.55)$ & $25.1(1.07)$ & -33.2 \\
\hline & $97.2(2.52)$ & $123.0(2.21)$ & +21.1 & $33.6(1.35)$ & $24.8(1.08)$ & -26.2 \\
\hline \multirow[t]{2}{*}{2} & $102.4(2.29)$ & $126.4(2.19)$ & +19.0 & $31.0(1.41)$ & $23.0(1.30)$ & -25.8 \\
\hline & $90.9(2.40)$ & $122.1(2.37)$ & +25.6 & $34.4(1.38)$ & $22.5(1.31)$ & -34.6 \\
\hline \multirow[t]{2}{*}{3} & $91.1(2.48)$ & $126.3(2.11)$ & +27.9 & $31.3(1.24)$ & $21.0(1.11)$ & -32.7 \\
\hline & $93.2(2.29)$ & $127.6(2.24)$ & +27.0 & $30.8(1.28)$ & $21.6(1.10)$ & -29.9 \\
\hline
\end{tabular}

Three separate preparations of cells were studied and two sets of subcellular fractions from each were separated and used within a week. Cells were exposed to PHA at $37^{\circ} \mathrm{C}$. Values are the $\mathrm{B}_{\mathrm{T}}$ in pmol/mg protein, with the $K_{\mathrm{d}}$ in $10^{-7} \mathrm{M}$ shown in parentheses, obtained by Scatchard plot analyses, similar to those of Fig. 3. * Increment $(+)$ or decrement $(-)$ in the percent changes in $\mathrm{B}_{\mathrm{T}}$ of PHA-treated samples from that of unstimulated control. 
Table II. Effect of DNP, KCN, and Temperature on the Glucose-sensitive CB Binding to Plasma Membrane and Microsomal Membranes without and with PHA Treatment

\begin{tabular}{|c|c|c|c|c|c|c|c|}
\hline \multirow{2}{*}{$\begin{array}{l}\text { Lymphocyte } \\
\text { preparations }\end{array}$} & \multirow[b]{2}{*}{ Conditions } & \multicolumn{3}{|c|}{ Plasma membrane } & \multicolumn{3}{|c|}{ Microsomal membrane } \\
\hline & & Control & PHA & \% Changes & Control & PHA & \% Changes \\
\hline \multirow[t]{2}{*}{1} & Control & $94.7(2.61)$ & $125.4(2.44)$ & +24.5 & $33.6(1.20)$ & $25.7(1.15)$ & -23.5 \\
\hline & DNP & $90.9(2.29)$ & $97.1(2.18)$ & +6.4 & $34.1(1.17)$ & $32.6(1.10)$ & -4.4 \\
\hline \multirow[t]{2}{*}{2} & Control & $88.1(2.61)$ & $117.0(2.43)$ & +24.7 & $34.0(1.36)$ & $27.2(1.11)$ & -20.0 \\
\hline & DNP & $85.9(2.29)$ & $89.7(2.54)$ & +4.2 & $36.5(1.21)$ & $34.2(1.42)$ & -6.3 \\
\hline \multirow[t]{2}{*}{3} & Control & $96.7(2.37)$ & $129.8(2.41)$ & +25.5 & $36.2(1.15)$ & $27.8(1.43)$ & -35.4 \\
\hline & DNP & $88.5(2.13)$ & $96.8(2.00)$ & +8.6 & $33.9(1.52)$ & $31.7(1.43)$ & -6.5 \\
\hline \multirow[t]{2}{*}{4} & Control & $92.9(2.33)$ & $121.8(2.41)$ & +23.7 & $34.1(1.28)$ & $26.6(1.24)$ & -22.0 \\
\hline & $\mathrm{KCN}$ & $87.7(2.43)$ & $100.0(2.48)$ & +11.4 & $32.8(1.32)$ & $29.2(1.08)$ & -10.9 \\
\hline \multirow[t]{2}{*}{5} & $21^{\circ} \mathrm{C}$ & $93.8(2.73)$ & $123.8(2.62)$ & +24.2 & $32.8(1.28)$ & $24.5(1.29)$ & -25.3 \\
\hline & $0^{\circ} \mathrm{C}$ & $90.0(2.18)$ & $90.3(2.22)$ & +0.3 & $30.7(1.35)$ & $31.3(1.21)$ & +1.9 \\
\hline \multirow[t]{2}{*}{6} & $21^{\circ} \mathrm{C}$ & $97.1(2.41)$ & $130.4(2.27)$ & +25.5 & $33.6(1.20)$ & $27.8(1.26)$ & -17.3 \\
\hline & $0^{\circ} \mathrm{C}$ & $92.9(2.33)$ & $94.7(2.45)$ & +1.9 & $31.1(1.61)$ & $30.2(1.18)$ & -2.9 \\
\hline
\end{tabular}

Values are $\mathrm{B}_{\mathrm{T}}$ in pmol/mg protein, with $K_{\mathrm{d}}$ in $10^{-7} \mathrm{M}$ shown inside the parentheses. Results using six separate cell preparations are depicted. Values represent the Scatchard analysis of equilibrium CB binding of subcellular fractions from a single cell preparation similar to that of Fig. 3. Also shown are the percent changes in $B_{T}$ due to PHA treatment as increment $(+)$ or decrement $(-)$ from the corresponding unstimulated control. Effects of DNP were studied in preparations 1, 2, and 3, while effects of $\mathrm{KCN}$ were studied in preparation 4. Effects of temperature were studied in preparations 5 and 6 by exposure of cells to PHA at $4^{\circ} \mathrm{C}$, followed by subcellular fractionation.

latory mechanism has been demonstrated in insulin-sensitive systems such as adipocytes $(10,11)$ and muscle cells $(21-24)$. Translocation of other types of transport carrier molecules has also been observed in stimulus-response systems that are not insulin dependent. Gluck et al. (25) have presented evidence of translocation of proton pump ATPase molecules when turtle bladder epithelium is stimulated to excrete acid by exposure to $\mathrm{CO}_{2}$. Our data constitutes the first demonstration of translocation of glucose carrier in lymphoid cells mediated by a mitogenic stimulus. This supports the possibility of commonality of this translocation mechanism in a wider variety of stimulus-response systems.

Our data clearly demonstrate that there is an authentic intracellular storage pool of glucose transporters (M-sites) in hPBMC. That this is not simply the contamination of plasma membrane is supported by the findings summarized in Table III. For unstimulated lymphocytes the specific activities of
5 -NT, a plasma membrane-specific enzyme marker in the microsomal fraction, is only $15 \%$ of that found in the plasma membrane fraction, indicating that contamination of plasma membrane in microsomal fraction is not more than $15 \%$. The maximum limit for contamination may be significantly less than this value, as $5^{\prime}$-NT is not present exclusively in the plasma membrane in rat lymphocytes, but is also found in an intracellular compartment although at a lower specific activity (26). The corresponding $M$-site concentration ratio calculated from values of $B_{\mathrm{T}}$ in $\mathrm{pmol} / \mathrm{mg}$ protein in these two fractions for control cells is 0.37 . This is much greater ( $>$ twofold) than the 0.15 calculated maximum plasma membrane contamination of the microsomal fraction. Therefore, the observed $\mathbf{M}$ site content in the microsomal fraction cannot be explained by the cross-contamination alone.

Three lines of evidence presented further establish the occurrence of translocation of M-sites within $60 \mathrm{~min}$ of PHA

Table III. Protein Recovery, 5'-NT Activities and Glucose-displaceable CB $B_{T}$ of Subcellular Fractions

\begin{tabular}{llccc}
\hline \multicolumn{1}{c}{ Fractions } & Treatments & Protein & $5^{\prime}$-NT specific activities & B B $_{\mathrm{T}}$ of M-site binding specific activities \\
\hline \multirow{3}{*}{ Homogenate } & & $\mu g / 10^{6} \mathrm{cells}$ & nmol/h per $\mu g$ protein & pmol/mg protein \\
& Control & $103 \pm 13$ & $0.185 \pm 0.022$ & ND \\
Plasma membrane & PHA & $108 \pm 10$ & $0.181 \pm 0.017$ & ND \\
& Control & $4.63 \pm 0.29$ & $1.541 \pm 0.318$ & $95.6 \pm 1.51$ \\
Microsomes & PHA & $4.75 \pm 0.29$ & $1.571 \pm 0.307$ & $125.1 \pm 3.70^{\ddagger}$ \\
& Control & $24.2 \pm 0.98$ & $0.231 \pm 0.004$ & $33.1 \pm 0.80$ \\
& PHA & $24.0 \pm 1.51$ & $0.233 \pm 0.003$ & $22.9 \pm 0.62^{\ddagger}$
\end{tabular}

Figures represent mean and SEM for results obtained from three mutually independent experiments. ${ }^{*}$ Lowry method used in protein determination. The method described by R. A. Weaver and W. Boyle (30) was used for determination of $5^{\prime}$-NT in subcellular fractions. ${ }^{\ddagger}$ Comparisons between control and PHA-stimulated cells were statistically significant $(P<0.01)$. For all other categories PHA stimulation did not have significant effects $(P>0.05)$. 
stimulation. First, PHA stimulation did not alter the distribution of this enzyme marker ( $\left.5^{\prime}-\mathrm{NT}\right)$, nor did stimulation alter the recovery of protein in the various fractions, but altered the distribution of M-sites significantly (Table III). Secondly, inhibition of metabolic activity by a variety of modalities (e.g., $\mathrm{DNP}, \mathrm{KCN}$, and low temperature) all lead to inhibition of PHA-induced M-site redistribution. It is unlikely that such a variety of unrelated alterations in experimental conditions could all lead to the same artifactual result (i.e., change in sedimentation characteristics). Moreover, each of these variations (DNP, KCN, and low temperature) are known to affect carrier translocation in adipocytes $(10,11)$. Finally, we have also presented evidence that the total number of glucose transporters/cell is unaffected in the first $60 \mathrm{~min}$ after PHA stimulation, which excludes significant increase due to synthesis of new glucose transporters during this brief time period.

In the hPBMC, unlike in adipocytes, the concentration (specific activity) of $\mathrm{M}$-sites in plasma membrane fraction is about threefold higher than that in the microsomes. Therefore, correction for contamination of plasma membrane fraction (with its relatively high specific activity of M-sites of 88-103 $\mathrm{pmol} / \mathrm{mg}$ protein) with microsomes that have a lower density of M-sites (30-35 pmol/mg protein) would, if anything, raise the concentration of $\mathrm{M}$-sites in plasma membrane to an even higher level. Precise estimation of microsomal contamination in the plasma membrane fraction is, therefore, not essential either for the demonstration of the authentic microsomal pool of glucose transporters or for demonstration of the occurrence of translocation. Despite considerable effort we have not yet been able to find a specific microsomal enzyme marker in hPBMC since the NADH:cytochrome $c$ as well as glucose-6phosphate phosphatase, the conventional microsomal markers, were found to exist indigenously in significant concentrations in the purified plasma membrane (data not presented). There is evidence that NADH-cytochrome $c$ reductase may not be a specific marker of microsomal fraction since the possibility exists that this enzyme may exist indigenously in the plasma membrane. Indeed, highly purified rat liver plasma membranes and Golgi apparatus have been shown to contain this enzyme with specific activities of 10 and $25 \%$ of that in the endoplasmic reticulum (27). In the rat adipocyte it has been assumed that the indigenous NADH-cytochrome $c$ reductase specific activity of the plasma membrane fraction may be $20 \%$ of that in uncontaminated microsomal membrane (10). In the absence of specific enzyme markers and detailed knowledge of the precise subcellular distribution of individual marker enzymes in human lymphocytes, precise quantitative estimation of cross-contamination of plasma membrane with microsomal fractions was not possible.

Whitesell et al. $(2,4)$ demonstrated that resting rat $\mathrm{T}$ lymphocytes consist of two populations defined by glucose transport rate only (e.g., a "quiescent" and an "active" subset). Further, mitogenic stimulation converted a significant fraction of the quiescent subset to the active status $(2,4)$. Our 3-OMG equilibrium exchange data (Fig. $2 A$ ) reproduce Whitesell's observations for the hPBMC population used here. The terms active and quiescent used here do not refer to the cell-cycle status.

An important question at this point is to what extent the observed recruitment (translocation) of the glucose carrier (M-sites) can account for the observed stimulation of glucose transport in PHA-stimulated cells. To answer this question from the 3-OMG exchange data, the translocation of the glucose carrier should be quantitated based on the observed population heterogeneity defined only in terms of transport rates and shift in the population sizes induced by PHA stimulation. Since PHA stimulation of the glucose flux in lymphocytes does not involve significant change in the $K_{\mathrm{m}}(1)$, one can convert the observed relative change in flux data measured at a fixed single substrate concentration into relative change in the number of carriers in the plasma membrane, assuming PHA stimulation does not involve any significant change in turnover number of each carrier. Since the flux rate of the active cells is $\sim$ fivefold higher than that of the quiescent cells (with $t_{1 / 2}$ of 3 and $15 \mathrm{~min}$, respectively), one can assign relative plasma membrane pool sizes of M-sites to be 5 and 1 (in arbitrary units)/cell for the active and quiescent subsets, respectively. Since the population sizes of the active and quiescent subsets are shifted (from 20 and $80 \%$ to 40 and $60 \%$ ) by PHA stimulation (Fig. 2) and the cellular M-sites were not increased (see above), the overall M-site plasma membrane pool size must have increased from 180 to $260 \mathrm{U} / 100$ cells. This is an increase of $44 \%$. The observed increase in M-sites in the plasma membrane was $\sim 26 \%$ (Table III), indicating that carrier translocation explains $\sim 60 \%$ of the increment in glucose transport caused by PHA. Simpson et al. have presented evidence that translocation of glucose transporters represents only one component in a complex mechanism through which insulin regulates glucose transport in adipocytes (28). It appears that in the PHA-stimulated human lymphocyte mechanisms other than translocation may play a role in augmenting glucose transport. 3-OMG equilibrium exchange was measured at $15^{\circ} \mathrm{C}$, unlike all other experiments including translocation reported here, which were performed at $37^{\circ} \mathrm{C}$ exclusively. Our estimates of glucose transport are based on the assumption that the increment due to PHA at $37^{\circ} \mathrm{C}$ is proportional to the increment when the experiment is performed at $15^{\circ} \mathrm{C}$, as it was here.

The temperature shift to $15^{\circ} \mathrm{C}$ by itself is known to cause redistribution of glucose transporters in rat adipocytes, which can be prevented by treatment of cells with $\mathrm{KCN}(2 \mathrm{mM})(29)$. However, we have shown that the increment in glucose transport caused by PHA was well preserved when cells were treated with $\mathrm{KCN}$ after PHA treatment before lowering temperature to $15^{\circ} \mathrm{C}$. Therefore, under the conditions used, the temperature shift cannot be responsible for most of the observed increment. Similar calculation made from the data after $\mathrm{KCN}$ treatment (not shown) essentially led to a similar conclusion. Data of 2-deoxy-glucose uptake measured at $37^{\circ} \mathrm{C}$ (Fig. 2 B) support the possibility that translocation mechanism can explain up to $25-30 \%$ of the PHA-induced increment in transport. We should state that quantitative analysis of net $2 \mathrm{DOG}$ uptake data in terms of transport is complicated due to its phosphorylation and to the fact that net uptake but not equilibrium exchange is being measured.

\section{Acknowledgments}

We thank Ms. Dawn Potter for artwork, Ms. Ruth Harvey for secretarial assistance, and Ms. J. Ballard for technical help.

Supported by designated research funds of the United States Veterans Administration and National Institutes of Health grant AM-13376. 


\section{References}

1. Peters, J. H., and P. Hausen. 1971. Effect of phytohaemagglutinins on lymphocyte membrane transport. 2. Stimulation of "facilitated diffusion" of 3-O-methyl-glucose. Eur. J. Biochem. 19:509-513.

2. Whitesell, R. R., R. A. Johnson, H. L. Tarpley, and D. M. Regen. 1977. Mitogen stimulated glucose transport in thymocytes: possible role of calcium and antagonism by adenosine-3-5-monophosphate. $J$. Cell Biol. 72:456-469.

3. Helderman, J. H. 1981. Role of insulin in the intermediary metabolism of activated thymic derived lymphocyte. J. Clin. Invest. 67:1636-1642.

4. Whitesell, R. R., and D. M. Regen. 1978. Glucose transport characteristics of quiescent thymocytes. J. Biol. Chem. 253:72897294.

5. Yasmeen, D. A., A. J. Lavid, D. A. Hume, and M. J. Weidemann. 1977. Activation of 3-O-methyl-glucose transport in rat thymic lymphocytes by concanavalin-A: temperature and calcium dependence and sensitivity to puromycin but not to cycloheximide. Biochim. Biophys. Acta. 500:89-100.

6. Hume, D. A., and M. J. Weidemann. 1978. On the stimulation of rat thymocyte 3-O-methyl glucose transport by mitogenic stimuli. $J$. Cell. Physiol. 96:303-308.

7. Kay, J. E. 1976. The importance of changes in membrane transport in lymphocyte activation by phytohaemagglutinin. Biochem. Soc. Trans. 4:1120-1123.

8. Hume, D. A., J. J. Radik, E. Ferber, and M. J. Weidemann. 1978. Aerobic glycolysis and lymphocyte transformation. Biochem. J. 174:703-709.

9. Mookerjee, B. K., J. Cuppoletti, A. L. Rampal, and C. Y. Jung. 1981. Effects of cytochalasins on lymphocytes: identification of distinct cytochalasin binding sites in relation to mitogenic stimulation and glucose transport. J. Biol. Chem. 256:1290-1300.

10. Cushman, S. W., and L. J. Wardzala. 1980. Potential mechanism of insulin action on glucose transport in the isolated rat adipose cell: apparent translocation of intracellular transport systems to the plasma membrane. J. Biol. Chem. 255:4758-4762.

11. Suzuki, K., and T. Kono. 1980. Evidence that insulin causes translocation of glucose transport activity to the plasma membrane from an intracellular storage site. Proc. Natl. Acad. Sci. USA. 77:2542-2545.

12. Jung, C. Y., and A. L. Rampal. 1977. Cytochalasin B binding site and glucose transport carrier in human erythrocyte ghosts. J. Biol. Chem. 252:5456-5463.

13. Mookerjee, B. K., and C. Y. Jung. 1982. Effects of cytochalasins on lymphocytes: mechanism of action of cytochalasin A on responses to phytomitogens. J. Immunol. 128:2153-2159.

14. Lichtman, A. H., G. B. Segel, and M. A. Lichtman. 1981. Calcium transport and calcium ATPase activity in human lymphocyte plasma membrane vesicles. J. Biol. Chem. 256:6148-6154.

15. Mookerjee, B. K., and C. Y. Jung. 1983. Effects of cytochalasins on lymphocytes: mechanism of inhibition of E-rosette formation. J. Immunol. 131:1126-1130.
16. Jacobs, D. B., B. K. Mookerjee, and C. Y. Jung. 1984. Furosemide inhibits glucose transport in isolated rat adipocytes by direct inactivation of carrier proteins. J. Clin. Invest. 74:1679-1685.

17. Martz, A., B. K. Mookerjee, and C. Y. Jung. 1986. Insulin and phorbol esters affect the maximum velocity rather than the half-saturation constant of 3-O-methyl glucose transport in rat adipocytes. J. Biol. Chem. 261:13606-13609.

18. Adams, H. 1963. Adenosine 5'-triphosphate determination with phosphoglycerate kinase. In Methods of Enzymatic Analysis. H. U. Bergmeyer, editor. Academic Press Inc., New York. 539-543.

19. Beutler, E. 1971. Red Cell Metabolism. Grune \& Stratton, New York. 243-247.

20. Slaunwhite, W. R., J. K. Goldman, and L. L. Bernardis. 1972. Sequential changes in glucose metabolism by adipose tissue and liver of rats after destruction of ventromedial hypothalmic nuclei: effect of three dietary regimens. Metab. Clin. Exp. 21:619-631.

21. Wardzala, L. J., and B. Jeanrenaud. 1983. Identification of the D-glucose inhibitable cytochalasin B binding site as the glucose transporter in the rat diaphragm plasma and microsomal membranes. Biochim. Biophys. Acta. 730:49-56.

22. Wardzala, L. J., and B. Jeanrenaud. 1981. Potential mechanism of insulin action on glucose transport in the isolated rat diaphragm. $J$. Biol. Chem. 256:7090-7093.

23. Watanabe, T., M. M. Smith, F. W. Robinson, and T. Kono. 1984. Insulin action on glucose transport in cardiac muscle. J. Biol. Chem. 259:13117-13122.

24. Oka, Y., and M. S. Czech. 1984. Photoaffinity labelling of insulin sensitive hexose transporters in intact rat adipocytes: direct evidence that latent transporters become exposed to the extracellular space in response to insulin. J. Biol. Chem. 259:8125-8133.

25. Gluck, S., C. Cannon, and Q. H. Awqati. 1982. Exocytosis regulates urinary acidification in turtle bladder by rapid insertion of $\mathrm{H}^{+}$pumps into the luminal membrane. Proc. Natl. Acad. Sci. USA. 769:4327-4331.

26. Stanley, K. K., M. R. Edwards, and J. P. Luzio. 1980. Subcellular distribution and movement of 5 '-nucleotidase in rat cells. Biochem. J. 186:59-79.

27. Huang, C. M., H. Goldenberg, C. Frantz, D. Morre, T. W. Kennan, and F. L. Crane. 1979. Comparison of NADH-linked cytochrome-C reductases of endoplasmic reticulum, Golgi apparatus and plasma membrane. Int. J. Biochem. 10:723-731.

28. Simpson, I. A., D. R. Yver, P. J. Hissin, L. J. Wardzala, E. Karnieli, L. B. Salans, and S. W. Cushman. 1983. Insulin stimulated translocation of glucose transporters in the isolated rat adipose cells: characterisation of subcellular fractions. Biochim. Biophys. Acta. 763:393-407.

29. Kono, T., K. Suzuki, L. E. Dansey, F. W. Robinson, and T. L. Bevins. 1981. Energy dependent and protein synthesis independent recycling of the insulin sensitive glucose transport mechanism in fat cells. J. Biol. Chem. 256:6400-6407.

30. Weaver, R. A., and W. Boyle. 1969. Purification of plasma membranes of rat liver: application of zonal centrifugation to isolation of cell membranes. Biochim. Biophys. Acta. 173:377-388. 